\title{
Modeling the density variation in the shallow firn layer
}

\author{
Jun LI, ${ }^{1}$ H. JAY ZWALLY ${ }^{2}$ \\ ${ }^{1}$ Raytheon ITSS, Code 971, NASA Goddard Space Flight Center, Greenbelt, MD 20771, U.S.A. \\ E-mail: lijun@icesat2.gsfc.nasa.gov \\ ${ }^{2}$ Ocean and Ice Branch, Code 971, NASA Goddard Space Flight Center, Greenbelt, MD 20771, U.S.A
}

\begin{abstract}
Vapor-transfer theory is incorporated into a previous firn-densification model to investigate the effect of vapor-transfer processes on densification in firn within $10 \mathrm{~m}$ of the surface. The densification rate in the model is governed by the change of overburden pressure (determined by the accumulation rate), the firn temperature, and the temperature gradient. The time of exposure to temperature gradients at shallow depths is a critical factor determining the importance of vapor-transfer processes. In high-accumulation and high-temperature conditions such as for the Greenland ice sheet, the temperature gradient and vapor transfer are less important due to the shorter exposure times. The high summer temperatures dominate the rate of densification and annual variations in density. In low-accumulation and low-temperature conditions, such as for inland Antarctica, the vapor transfer driven by the temperature gradient has a stronger effect on the densification rate, and temperature-driven processes are less important. These factors determine both the rate of density increase with depth and the amplitudes of annual variations in density with depth.
\end{abstract}

\section{INTRODUCTION}

Recent modeling of firn densification and its effects on surface elevation indicates that firn densification near the surface (top several meters) is important in the interpretation of temporal variations in altimetry measurements (Arthern and Wingham, 1998; Zwally and Li, 2002). However, densification processes are complicated by the involvement of multiple processes (Paterson, 1994). Although there is no universal physical model for predicting densification rates in the firn column, several semi-empirical densification models (e.g. Herron and Langway, 1980; Spencer and others, 2001) and physically based models (e.g. Wilkinson and Ashby, 1975; Alley, 1987), which cope with the different processes dominant at particular stages of the densification, have been developed. The densification rates in these models are primarily governed by the overburden pressure (or the change of pressure) and the firn temperature. Therefore, these models are forced by the accumulation rate and surface air-temperature variations. Based on laboratory experiments on crystal growth and ice creep, Zwally and Li (2002) introduced a temperature-dependent activation energy and rate constant in their densification-elevation model and applied the model to the Summit of Greenland. That treatment increased the sensitivity of the densification rate to temperature, resulting in density variations compatible with field density profiles and seasonal elevation changes compatible with those observed in radar altimeter data over most of the Greenland ice sheet (Li and others, 2003).

Under conditions such as for inland Antarctica, both accumulation and firn temperature are much lower than in Greenland. The modeled magnitude of density variations quickly reduces with decreasing accumulation rate and temperature. However, a smaller magnitude of variation

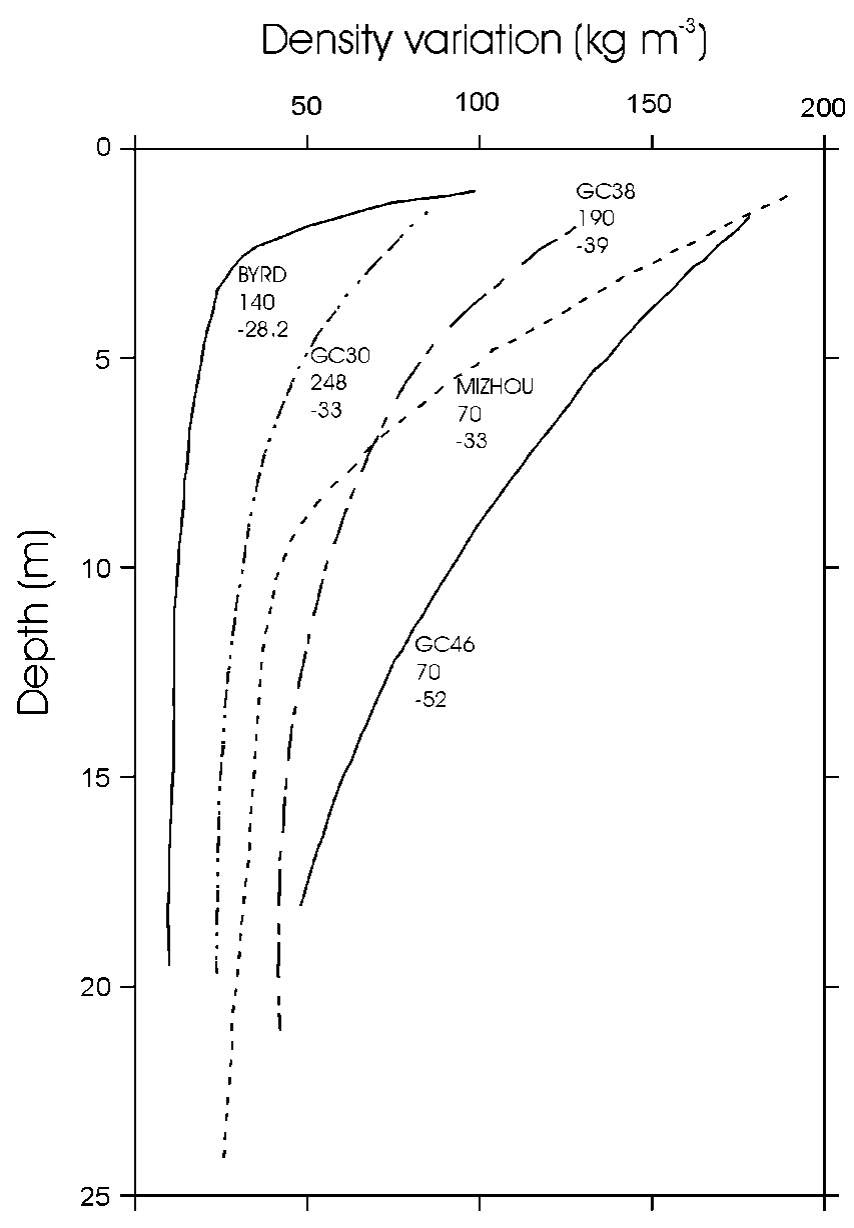

Fig. 1. Range of the density variation vs depth at different sites in the Antarctic ice sheet. The variation is calculated at a depth interval of $1 \mathrm{~m}$. The name of the station, accumulation rate $\left(\mathrm{kg} \mathrm{m}^{-2} \mathrm{a}^{-1}\right)$ and annual mean temperature $\left({ }^{\circ} \mathrm{C}\right)$ are indicated. After Qin and Young (1988b). 


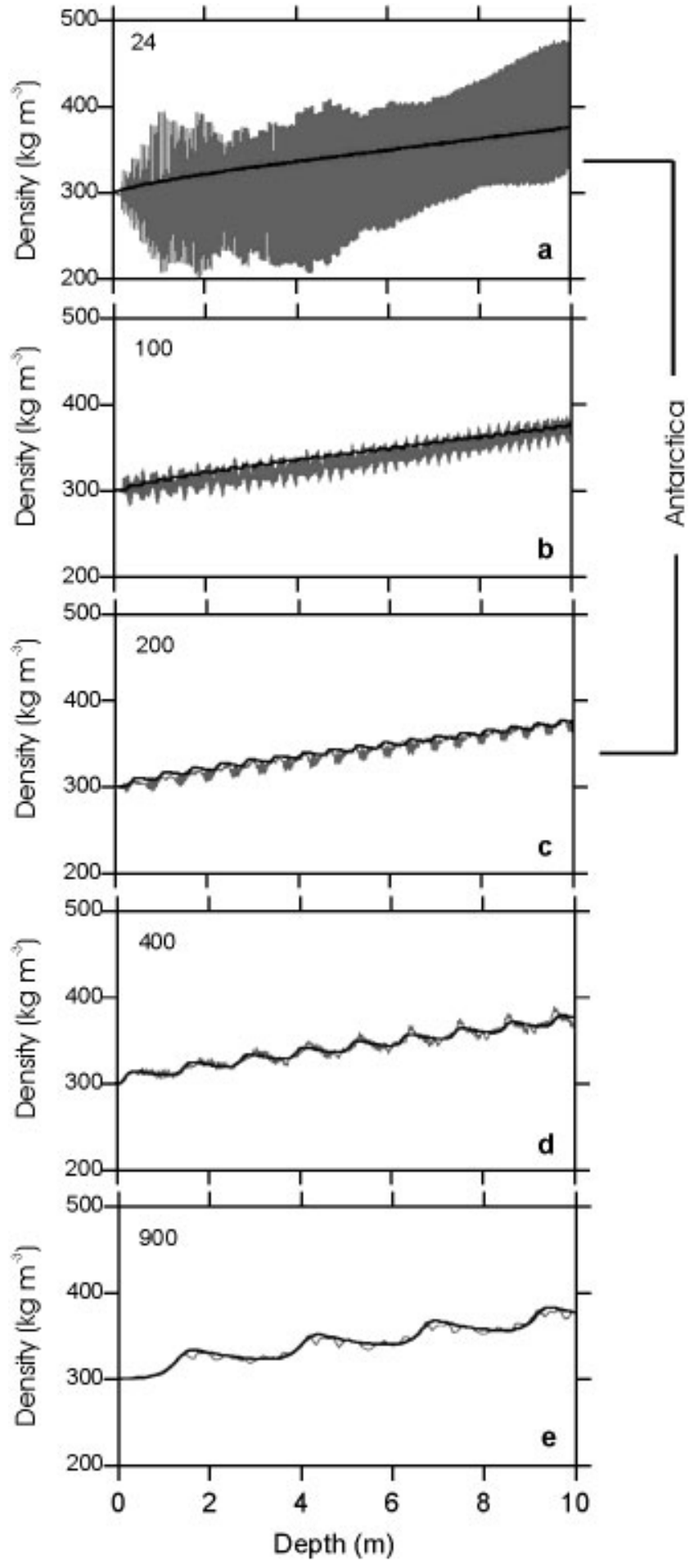

Fig. 2. Modeled density profiles (thin solid lines) in lowtemperature conditions with various accumulation rates: (a) 24, (b) 100, (c) 200, (d) 400 and (e) $900 \mathrm{~kg} \mathrm{~m}^{-2} a^{-1}$. Thicker solid lines show the density profiles without the consideration of vapor flow (i.e. $R_{\mathrm{v}}=0$ ). Surface temperatures with annual mean $-57^{\circ} \mathrm{C}$ and maximum $-17^{\circ} \mathrm{C}$ are applied for all model runs. The range of accumulation for the inland Antarctic ice sheet is also indicated, showing decreasing amplitude in the density variation with increasing accumulation rate.

has not been found either in density profiles or in seasonal elevation variations from satellite altimetry measurements. In fact, the opposite trend of density variations has been observed. Qin and Young (1988a) made a detailed study of density variations based on data measured continuously at $10 \mathrm{~cm}$ intervals in a number of firn cores collected from East
Antarctica. Together with data collected from Byrd Station, West Antarctica (Gow, 1968), they found that the density variability systematically increases with decreasing accumulation rate $\left(70-248 \mathrm{~kg} \mathrm{~m}^{-2} \mathrm{a}^{-1}\right)$ and annual mean temperature $\left(-28.2\right.$ to $\left.-52.2^{\circ} \mathrm{C}\right)$ with magnitude greater than $100-200 \mathrm{~kg} \mathrm{~m}^{-3}$ in the first $2 \mathrm{~m}$ of depth (Fig. 1; Qin and Young, 1988b). It has been recognized that models driven by accumulation and surface temperature cannot describe density variations successfully in the top few meters of firn (e.g. Alley, 1987, 1988). This may imply that other processes that are important to the densification have not been properly considered in the constitutive relation used in the models. Shallow firn is well exposed to airflow, subjecting the firn to extreme temperature gradients. Besides the pressure and temperature, field observations show that the vapor flow driven by the temperature gradient plays an important role in the firn metamorphism associated with large firn-density variations (e.g. Sturm and Benson, 1997). Vapor transportation in polar firn has been well studied both theoretically and experimentally (e.g. Colbeck, 1983). Studies have been focused mainly on the extraordinary snow crystal growth that is responsible for depth-hoar formation.

In this study, we incorporate available vapor-transfer theory into our pre-developed densification model (Zwally and $\mathrm{Li}, 2002$ ) to examine density variations during the densification in firn to depths of $10 \mathrm{~m}$.

\section{MODEL PHYSICS}

The densification model used here is modified from the model developed by Zwally and Li (2002). Based on the semi-empirical densification-rate equation derived by Herron and Langway (1980), the densification rate $\mathrm{d} \rho / \mathrm{d} t$ is given by:

$$
\mathrm{d} \rho / \mathrm{d} t=K(T) A^{\alpha}\left(\rho_{\mathrm{i}}-\rho\right) / \rho_{\mathrm{i}},
$$

where $K$ is solely dependent on temperature and $A$ is the mean accumulation rate, representing the change of overburden pressure. The factor $\alpha$ is approximately equal to 1 . The temperature dependence of the densification rate is taken to follow the Arrhenius relation:

$$
K(T)=K_{0}(T) \exp (-E(T) / R T) .
$$

According to laboratory experiments for ice crystal growth and deformation (Jacka and Li, 1994), Zwally and Li (2002) incorporated temperature-dependent rate constant $K_{0}(T)$ and activation energy $E(T)$ into the $K(T)$ function shown by Equation (2). Both parameters have usually been taken to be constants independent of temperature. To account for differences between the rates for processes of densification and crystal growth, they also introduced an empirical constant $\beta$ in the rate factor $K_{0}(T)$,

$$
K_{0}(T)=\beta K_{0 \mathrm{G}}(T) .
$$

$\beta$ is treated as an adjustable parameter used to calibrate the modeled density profiles according to observed density profiles.

Although the above treatment increases the sensitivity of the densification rate to temperature, resulting in an amplitude that is compatible with the observed seasonal density variation induced by seasonal temperature variations for most of the Greenland ice sheet ( $\mathrm{Li}$ and others, 2003), this accumulation- and temperature-forced model predicts very small density variations for low-accumulation, low-temperature conditions, as shown by Figure $2 \mathrm{a}-\mathrm{c}$. 
We now incorporate vapor-transport theory to modify the densification rate $\mathrm{d} \rho / \mathrm{d} t$. When a temperature gradient exists in the snow cover, the gradient causes heat and vapor flow in the direction of lower temperatures. During the summer, surface air temperature is normally higher than firn temperature, and vapor flow transports mass from upper firn layers to lower layers, enhancing the total densification rate. In winter, vapor flows upwards due to the opposite direction of the temperature gradient, reducing the densification rate. Here we assume that any upward vapor flow escapes into the surface atmosphere, so there is no contribution to the firn-layer thickness change. $\mathrm{d} \rho / \mathrm{d} t$ consists of two terms,

$$
\mathrm{d} \rho / \mathrm{d} t=R_{\mathrm{a}}+R_{\mathrm{v}} .
$$

The first term, $R_{\mathrm{a}}$, is due to accumulation rate and temperature given by Equation (1). The second term, $R_{\mathrm{v}}$, is caused by vapor transport driven by a temperature gradient. The densification rate of a firn layer due to vapor condensation or sublimation can be expressed in terms of the depth gradient of vapor flux $J$,

$$
R_{\mathrm{v}}=\frac{\partial \rho}{\partial t}=-\frac{\partial J}{\partial z} .
$$

The vapor flux $J$ can be expressed as

$$
J=-D_{\text {eff }} \frac{p_{0}}{R^{2}} \frac{L-R T}{T^{3}} \exp \left[\frac{L}{R}\left(\frac{1}{T_{0}}-\frac{1}{T}\right)\right] \frac{\partial J}{\partial z},
$$

where $D_{\text {eff }}$ is the coefficient of vapor diffusion in snow, $p_{0}$ and $T_{0}$ are triple point pressure $(610.5 \mathrm{~Pa})$ and temperature $(273.1 \mathrm{~K}), L$ is latent heat of sublimation $\left(2838 \times 10^{3} \mathrm{~J} \mathrm{~kg}^{-1}\right)$ and $R$ is the gas constant for water vapor $\left(461 \mathrm{~J} \mathrm{~K}^{-1} \mathrm{~kg}^{-1}\right)$. For the value of $D_{\text {eff }}$, Colbeck (1993) has indicated that the coefficient of vapor diffusion in snow is more than five times greater than its value in air $\left(22 \times 10^{-6} \mathrm{~m}^{2} \mathrm{~s}^{-1}\right)$. We follow this suggestion and set $D_{\text {eff }}=5 \times 22 \times 10^{-6} \mathrm{~m}^{2} \mathrm{~s}^{-1}$ as an approximation. Details of the derivation of Equations (5) and (6) and the parameters used have been given by Colbeck (1983, 1989, 1990, 1993) and Sturm and Benson (1997).

The above equations are coupled with the standard onedimensional time-dependent heat-transfer equation and solved using a multi-layer numerical model (Zwally and $\mathrm{Li}, 2002$ ).

The temperature gradients are calculated at $0.01 \mathrm{~m}$ depth intervals based on the depth-temperature profile at each time $t$. A time-step of 10 days was used for the computation, giving the initial thickness of each firn layer as approximately $3 \%$ of the annual accumulation.

\section{RESULTS AND DISGUSSION}

In order to demonstrate the density variations, two cases are selected to run the model. One is a low-temperature, low-accumulation regime that is appropriate to inland Antarctica. A surface air temperature (annual mean $-57^{\circ} \mathrm{C}$, maximum $-17.0^{\circ} \mathrm{C}$ ) approximate to that for Vostok (annual mean $-57^{\circ} \mathrm{C}$, accumulation rate $24 \mathrm{~kg} \mathrm{~m}^{-2} \mathrm{a}^{-1}$; cf. Paterson, 1994, p. 210) is used. The second case is a high-temperature, high-accumulation regime that is closer to Greenland conditions. The temperature at the Summit of Greenland (annual mean $-30^{\circ} \mathrm{C}$, maximum $-2{ }^{\circ} \mathrm{C}$, accumulation rate $250 \mathrm{~kg} \mathrm{~m}^{-2} \mathrm{a}^{-1}$; Shuman and others, 2001) is used. In both cases, accumulation rates vary from $<100$ to a maximum of $900 \mathrm{~kg} \mathrm{~m}^{-2} \mathrm{a}^{-1}$. All other parameters are kept constant

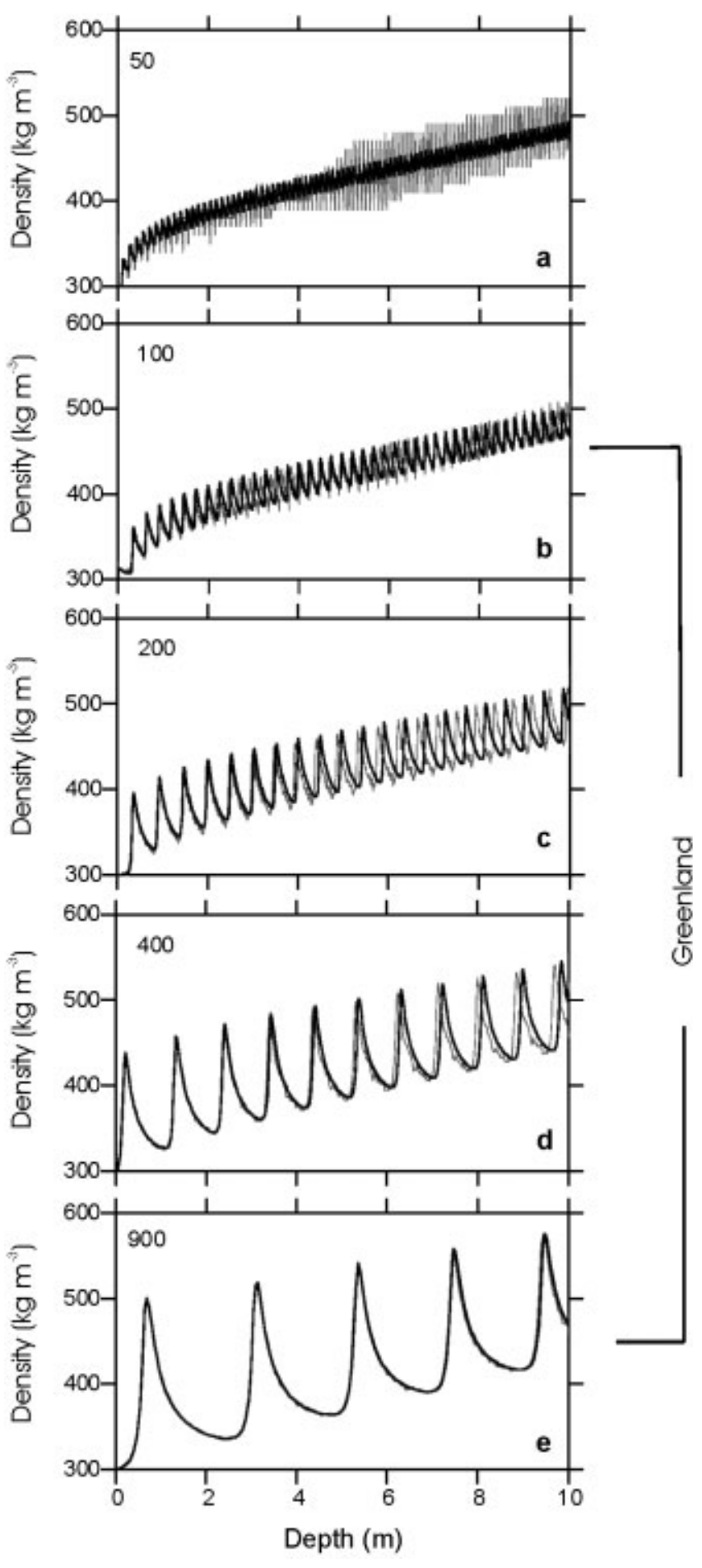

Fig. 3. Modeled density profiles (thin solid lines) in hightemperature conditions with various accumulation rates: (a) 50, (b) 100, (c) 200, (d) 400 and (e) $900 \mathrm{~kg} \mathrm{~m}^{-2} \mathrm{a}^{-1}$. Thicker solid lines show the density profiles without the consideration of vapor flow (i.e. $R_{\mathrm{v}}=0$ ). Surface temperatures with annual mean $-30^{\circ} \mathrm{C}$ and maximum $-2^{\circ} \mathrm{C}$ are applied for all model runs. The range of accumulation for the accumulation area of the Greenland ice sheet is also indicated, showing increasing amplitude in the density variation with increasing accumulation rate.

(Fig. 2) in order to show the accumulation-rate dependence. However, the accumulation rate for the dry-snow zone in Antarctica is essentially $<200 \mathrm{~kg} \mathrm{~m}^{-2} \mathrm{a}^{-1}$ (Giovinetto and Zwally, 2000) and $>100 \mathrm{~kg} \mathrm{~m}^{-2} \mathrm{a}^{-1}$ for most of the Greenland accumulation area (Zwally and Giovinetto, 2000), as indicated in Figures 2 and 3 respectively. 


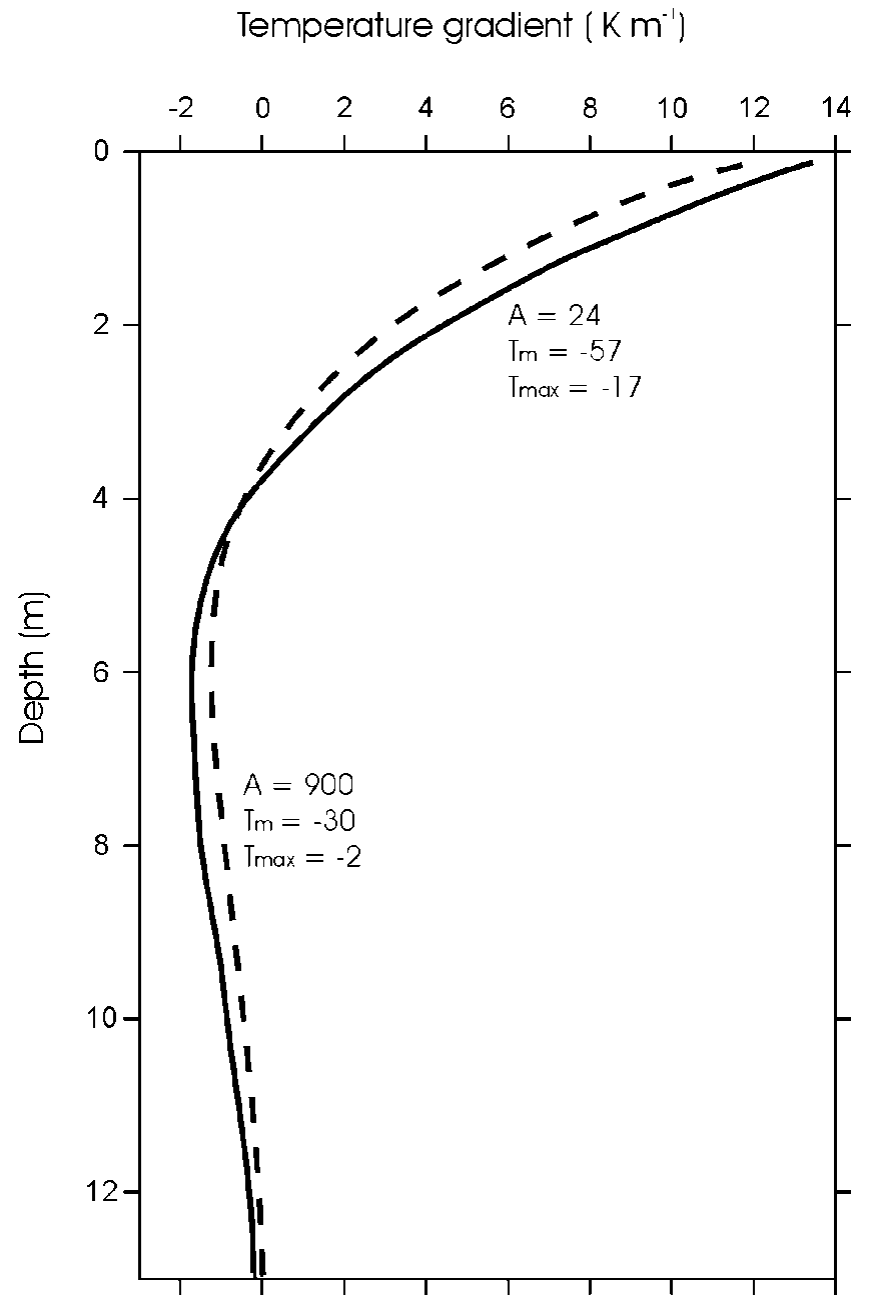

Fig. 4. Calculated temperature-gradient profiles for the two extreme surface conditions. The accumulation rate $A\left(\mathrm{~kg} \mathrm{~m}^{-2} \mathrm{a}^{-1}\right)$, annual mean temperature $T_{\mathrm{m}}\left({ }^{\circ} \mathrm{C}\right)$ and maximum temperature $T_{\max }\left({ }^{\circ} \mathrm{C}\right)$ used for the model inputs are indicated in the diagram.

Since the densification law used (Equation (1)) is semiempirical, the rate constant has to be determined empirically according to observed density profiles (Herron and Langway, 1980). Zwally and Li (2002) used $\beta=8$ to match the observed density profile for the Summit of Greenland. Recently, Li and others (2003) examined density profiles at multiple sites over the Greenland ice sheet. They found that $\beta$ must be dependent on annual mean temperature to allow the best agreement between modeled density profiles and field data. According to their regression relation between $\beta$ and annual mean temperature, two values of $\beta=18$ and 8 that give the best fits to the field density profiles at Vostok and the Greenland summit are respectively applied to the above two cases. Surface snow density was set to $300 \mathrm{~kg}$ $\mathrm{m}^{-3}$ as a constant. Sinusoidal variation of the surface air temperature during the year is assumed.

Figures 2 and 3 present the modeled density variations. The corresponding profiles modeled without the consideration of vapor flow $\left(R_{\mathrm{v}}=0\right)$ are also included for comparison. Figure $2 \mathrm{a}-\mathrm{c}$ show striking features for the lowtemperature, low-accumulation case. At accumulation rate $A=24 \mathrm{~kg} \mathrm{~m}^{-2} \mathrm{a}^{-1}$ (Vostok; Fig. 2a), vapor flow affects the densification significantly, causing large variations in the density profile. The density ranges from about 200 to $400 \mathrm{~kg} \mathrm{~m}^{-3}$ along the general slowly increasing trend. If the

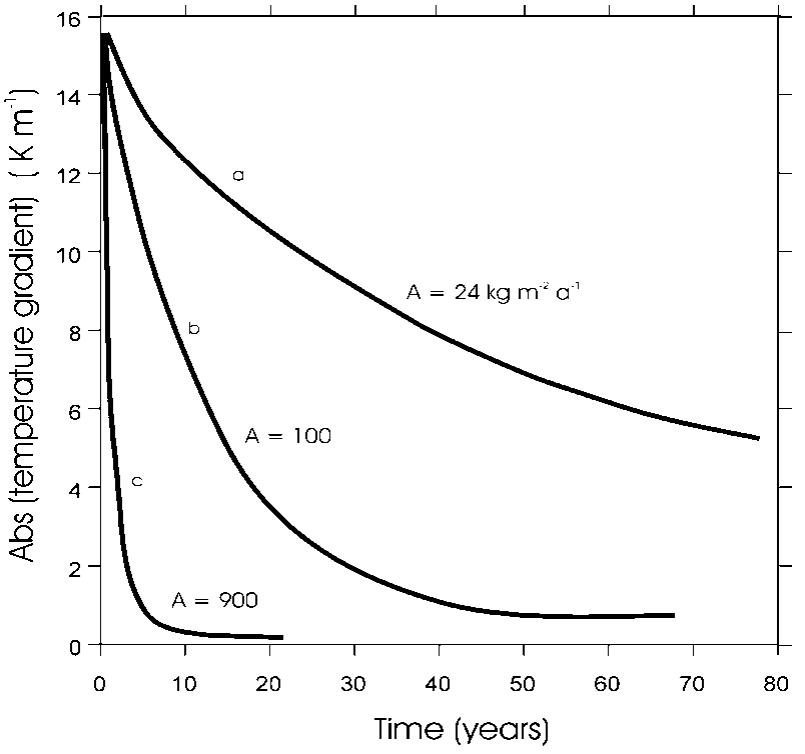

Fig. 5. Modeled magnitude of the temperature-gradient profiles for three selected accumulation rates, showing the decreasing magnitude of temperature gradient experienced by a firn layer with increasing accumulation rate. The accumulation rates used are 24, 100 and $900 \mathrm{~kg} \mathrm{~m}^{-2} a^{-1}$. The input surface temperature is taken as for Figure 2.

vapor flow is not considered, i.e. $R_{\mathrm{v}}=0$, the corresponding density profile shown by the thick solid line (Fig. 2a) indicates that the variability of the density is approximately zero. The difference is obvious. The variability sharply reduces to $20 \mathrm{~kg} \mathrm{~m}^{-3}$ (Fig. 2c) when accumulation rate increases to $200 \mathrm{~kg} \mathrm{~m}^{-2} \mathrm{a}^{-1}$. Further increasing the accumulation rate even to $900 \mathrm{~kg} \mathrm{~m}^{-2} \mathrm{a}^{-1}$ seems to have little effect on the magnitude of the variation (Fig. 2d-e).

By contrast, in the high-temperature, high-accumulation case (Fig. 3b-e), with increasing accumulation rate from 100 to $900 \mathrm{~kg} \mathrm{~m}^{-2} \mathrm{a}^{-1}$ the density variation increases from approximately 50 to $200 \mathrm{~kg} \mathrm{~m}^{-3}$. Comparing both density profiles in each diagram, the density variations are little affected by vapor flow driven by the temperature gradient. The two curves are almost completely overlapped when the accumulation rate reaches $900 \mathrm{~kg} \mathrm{~m}^{-2} \mathrm{a}^{-1}$ (Fig. 3e). In this case, the densification rate is essentially given by Equation (1). From Equation (1) for the same temperatures, larger accumulation rates $\mathrm{A}$ increase the densification rate $\mathrm{d} \rho / \mathrm{d} t$, resulting in higher firn density during the summer period. In winter, the densification process is much retarded due to the colder temperatures ( $\mathrm{Li}$ and Zwally, 2002). Larger accumulation rates allow the newly deposited firn to travel to greater depth. Thus the lower density of this firn is better preserved since it is not as affected by the next summer's higher temperatures. It is shown by Figure $3 \mathrm{~b}-\mathrm{e}$ that the minimum peak densities of each seasonal cycle decrease from approximately 470 to $420 \mathrm{~kg} \mathrm{~m}^{-3}$ at $10 \mathrm{~m}$ with increasing accumulation rate from 100 to $900 \mathrm{~kg} \mathrm{~m}^{-2} \mathrm{a}^{-1}$. As a consequence, the density variation increases with increasing accumulation rate.

The major cause of the large variability in density in the low-temperature, low-accumulation case (e.g. Fig. 2a) is the time of exposure to temperature gradients. This period depends upon the accumulation rate. At low-accumulation sites, each deposited firn layer remains near the surface and exposed to the extreme temperature gradient for a longer period. The importance of the temperature gradient thus 
weakens with increasing accumulation rate. Figure 4 shows the calculated temperature-gradient profiles for the two extreme cases (Figs 2a and 3e). Comparing these two cases, although the accumulation rate and surface temperature are extremely different, the temperature-gradient profiles do not show large differences. As expected, the magnitude of the temperature gradient quickly declines with increasing depth from approximately $12-15 \mathrm{~K} \mathrm{~m}^{-1}$ near the surface to approximately $1-2 \mathrm{~K} \mathrm{~m}^{-1}$ around $6 \mathrm{~m}$, then further reduces gradually towards zero at depths $>10 \mathrm{~m}$. However the temperature-gradient history experienced by a firn layer varies greatly at different accumulation levels. Figure 5 presents the history of a firn layer since its deposition for three selected accumulation rates $\left(24,100\right.$ and $\left.900 \mathrm{~kg} \mathrm{~m}^{-2} \mathrm{a}^{-1}\right)$. The input surface temperature is taken as for Figure 2. Each curve (a, b, c) in Figure 5 indicates the magnitude of the temperature gradient at the corresponding accumulation level. Clearly, firn at a lower-accumulation site (e.g. curve a) experiences larger temperature gradients for a longer amount of time simply because it travels to shallower depth in comparison with the high-accumulation sites (e.g. curve c).

\section{GONGLUSION}

The characteristics of density variations observed from inland Antarctica (Fig. 1) are described by our densification model. The time of exposure to temperature gradients at shallow depths determined by the accumulation rate is essential to the density variations. In a low-accumulation, low-temperature region such as inland Antarctica, the temperature gradient has a strong effect on the densification rate and thus the density variation. In higher-accumulation, higher-temperature conditions such as for the Greenland ice sheet, the temperature gradient becomes less important due to the shorter period of exposure. The accumulation rate and high summer temperature dominate the density variation.

\section{AGKNOWLEDGEMENTS}

This work was supported by the NASA Ice, Cloud and land Elevation Satellite (ICESat) project. We thank M. Beckley for help in preparing the graphics.

\section{REFERENGES}

Alley, R. B. 1987. Firn densification by grain-boundary sliding: a first model. 7. Phys. (Paris), 48, Colloq. Cl, 249-254. (Supplément au 3.)

Alley, R. B. 1988. Concerning the deposition and diagenesis of strata in polar firn. f. Glaciol., 34(118), 283-290.

Arthern, R. J. and D. J. Wingham. 1998. The natural fluctuations of firn densification and their effect on the geodetic determination of ice sheet mass balance. Climatic Change, 40(4), 605-624.

Colbeck, S. C. 1983. Theory of metamorphism of dry snow. F. Geophys. Res., 88(C9), 5475-5482.

Colbeck, S. C. 1989. Snow-crystal growth with varying surface temperatures and radiation penetration. 7. Glaciol., 35(119), 23-29.

Colbeck, S. C. 1990. Correspondence. Vapor-pressure dependence on temperature in models of snow metamorphism. F. Glaciol., 36(124), 351-353.

Colbeck, S. C. 1993. The vapor diffusion coefficient for snow. Water Resour. Res., 29(1), 109-115.

Giovinetto, M. B. and H. J. Zwally. 2000. Spatial distribution of net surface accumulation on the Antarctic ice sheet. Ann. Glaciol., 31, 171-178.

Gow, A. J. 1968. Deep core studies of the accumulation and densification of snow at Byrd Station and Little America V, Antarctica. CRREL Res. Rep. 197.

Herron, M. M. and C. C. Langway, Jr. 1980. Firn densification: an empirical model. f. Glaciol., 25(93), 373-385.

Jacka, T. H. and Jun Li. 1994. The steady-state crystal size of deforming ice. Ann. Glaciol., 20, 13-18.

Li Jun and H. J. Zwally. 2002. Modeled seasonal variations of firn density induced by steady-state surface air-temperature cycle. Ann. Glaciol., 34, 299-302.

LiJun, H. J. Zwally, H. Cornejo and D. Yi. 2003. Seasonal variation of snowsurface elevation in North Greenland as modeled and detected by satellite radar altimetry. Ann. Glaciol., 37, 233-238.

Paterson, W. S. B. 1994. The physics of glaciers. Third edition. Oxford, etc., Elsevier.

Qin Dahe and N.W. Young. 1988a. Characteristics of the initial densification of snow/firn in Wilkes Land, East Antarctica. [Abstract.] Ann. Glaciol., 11, 209.

Qin Dahe and N.W. Young. 1988b. [Characteristics of the initial densification of snow/firn in Wilks land Antarctica.] In Xie Zichu, ed. [A collection of Antarctic scientific explorations: studies in glaciology]. Beijing, Science Publishing House, 60-74. (Studies on Glaciology 5.) [In Chinese with English summary.]

Shuman, C. A., K. Steffen, J. E. Box and C. R. Stearns. 2001. A dozen years of temperature observations at the Summit: central Greenland automatic weather stations 1987-1999. 7. Appl. Meteorol., 40(4), 741-752.

Spencer, M. K., R. B. Alley and T. T. Creyts. 2001. Preliminary firn-densification model with 38-site dataset. F. Glaciol., 47(159), 671-676.

Sturm, M. and C.S. Benson. 1997. Vapor transport, grain growth and depth-hoar development in the subarctic snow. F. Glaciol., 43(143), 42-59.

Wilkinson, D. S. and M. F. Ashby. 1975. Pressure sintering by power law creep. Acta Metall., 23(11), 1277-1285.

Zwally, H. J. and M. B. Giovinetto. 2000. Spatial distribution of net surface mass balance on Greenland. Ann. Glaciol., 31, 126-132.

Zwally, H. J. and Li Jun. 2002. Seasonal and interannual variations of firn densification and ice-sheet surface elevation at the Greenland summit. f. Glaciol., 48(161), 199-207. 